\title{
Crossing the Valley of Death - An integrated framework and a value chain for emerging technologies
}

\begin{abstract}
The paper develops an integrated technology-push and market-pull framework, and a value chain model for crossing the Valley of Death (VOD-the gap between laboratory and market) for emerging technologies, based on primary and secondary data analyses and a survey conducted on European research and development projects. The study uses a case of micro and nanomanufacturing technology (MNT) and confirms the existence of the VOD through the survey data analysis. A mixed-methods approach was adopted which investigated the business and technical challenges to the commercialization of MNT. A notable finding is that the emerging MNT often does not have a direct link with market demand and the result suggests that an intermediary role between advanced technology and market demand should be integrated to act as coordinator for overcoming the VOD. The paper also examines how an intermediary is crucial to escape the VOD, within the value chain of the interdependent relationships between actors.
\end{abstract}

Index Terms - technology-push, market-pull, intermediaries, valley of death, emerging technology

\section{INTRODUCTION}

Nowadays, manufacturing is recognized as an important driver of a nation's wealth. There is a strong emphasis on obtaining more innovation from research, and cooperation between the worlds of science and business, within the European Union [1], which supports the need to investigate the typical 'technology-push' nature of science, and 'market-pull' nature of business, and to develop an integrated technology-push and market-pull framework, for crossing the VOD in emerging technologies, such as MNT. There are two dominant factors affecting manufacturing industry: the relentless pace of technological development and globalization. To survive in such a competitive environment, it is important to focus on the development and exploitation of key emerging technologies and on the development of 'innovation platforms', where the integration of a range of technologies, and the better coordination of policy and procurement, will result in a step change in performance. To some extent, technology is a means by which manufacturing firms can strive to ensure economic sustainability and competitiveness in this difficult and uncertain environment. On the other hand, the rapid rate of technological change, and associated shorter product life cycles, are part of the challenge [2].

The economics of technological innovation have been one of the central issues in technology management. The literature commonly talks about sustaining technologies and disruptive technologies [3], [4], with particular emphasis on consumer products [5], [6]. "Sustaining" technologies typically support current manufacturing practices and product performance, and are evolutionary or incremental in their development. In contrast, disruptive technologies typically do not support traditional firm-based manufacturing practices. In addition, disruptive technologies generate products with different performance attributes that require early-adopters to significantly change their behavior to use the innovation [7]. Manufacturing industry must innovate in those high-tech activities that offer added-value, rather than on improving existing technologies and products [8]. It seems quite clear, therefore, that small scale technologies are very capable of meeting these requisites. The emerging micro- and MNT is one example of disruptive and small scale technologies. For the purpose of this paper, MNT refers to a wide range of technologies used to fabricate structures at the micro and nano scale, such as structuring processes, biological components, and products using nanoparticles or more complex systems, such as lab-on chip devices. Thus, MNT comprises a wide range of approaches that are quite heterogeneous, with regards to their subjects of investigation, possible applications and imaginable periods of realization. Studies highlighting MNT as a disruptive technology, and the importance of developing MNT innovation models, have been carried out by e.g. Kautt et al. [9], Romig Jr et al. [10] and all the references therein.

Technologies for micro and nano multi-material processing, including 3D structuring technologies, are becoming more and more important for innovative applications, in practically all manufacturing sectors, since they enable flexible and cost-efficient manufacturing of multifunctional products made of different materials [11], [12]. In addition to functional integration, MNT introduces significant improvements in product manufacturing techniques, all of which can dramatically disrupt the way a new, innovative product should be designed. However, such multifunctional integration requires multidisciplinary expertise, and the use 
of complex process-chains, which utilize the capabilities of a large number of new technologies. The disparate nature of expertise and high capital investment required to use these technologies, coupled with the rapid advance in capabilities, makes it difficult for product designers to keep abreast of what can be achieved. As such, it is hypothesized that product innovation based on MNT is likely to be hindered, thus not realizing its full potential. Rapid advances in MNT have created a dilemma for organizations as to whether they should, and how they might, implement these technologies successfully. These technologies do not have a proven path from scientific discovery to mass production and therefore require novel approaches for crossing the VOD [13[-[16]. The underlying motivation, and driving forces, behind the innovation of such emerging technologies, are described by the concepts of technology-push and market-pull [17]-[22]. A fuller understanding of this area is required to bridge the gap between the laboratory and the market (VOD) and so ensure the successful commercialization of MNT-based products.

A thorough review of literature on technology-push and market-pull was essential in order to understand how MNT relates to technology-push and market-pull. A systematic literature review process was used for this, which provides some key classifications on how the technology-push and market-pull theories have been used to examine technological innovation processes. More importantly, the review serves as the basis of our proposition for extending the concepts further, and to develop an integrated framework in the context of emerging and disruptive technologies, such as MNT. The results of the review clearly suggest that the traditional framework is too simplistic and leads to a tendency to treat the concepts of technology-push and market-pull as two extreme elements, supporting our motivation to extend the framework. Based on primary and secondary data analyses and the responses to a survey performed on 88 European research and development projects of the Multi-Material Micro Manufacture (4M) community in Europe, an integrated technology-push and market-pull framework introduced to address the following research question: How do intermediaries facilitate crossing the VOD, for emerging technologies such as MNT. To accomplish our research objective, a value chain model is also developed, for the case of MNT, to validate the framework and to show how the intermediaries help to get through VOD, while combining push and pull strategies.

It is important to recall that disruptive or radical technological change is a function of the capacity to turn science-based inventions into commercially viable innovations. Research and experience show that one of the well-known roadblocks in the innovation process [14], [23] is the so-called VOD, which describes how R\&D projects, originating from basic scientific research, fail to reach commercialization/application. The notion of a 'VOD' is so pervasive in industry that the term appears somewhat matter-of-facty in engineering and manufacturing literature [13]-[16], as many new products simply disappear in the product development VOD, partly due to manufacturing costs, and limited product development budgets, coordination problems, and an inability to secure funding in order to progress to the next level of innovation.

This study makes two important contributions. First, it contributes to technology-push and market-pull literature by introducing an integrated technology-push and market-pull framework, where the intermediary role lies between the technology-push and market-pull inherent in the traditional framework. The existence of VOD, in the MNT innovation process, is confirmed in our survey, which supports our proposition of including the intermediaries in the technology-push and market-pull dynamic. Second, this study improves our understanding of the relationship between the role of intermediaries and the VOD, where the intermediaries were able to improve the speed and quality of the technology transfer under development. We show how intermediaries leverage inter-organizational collaboration ("value chain") and remove the barriers in the context of MNT commercialization. This also suggests that the intermediary role is crucial to escape from the VOD, turning technologies into full commercial and business successes. To support and validate the importance of the intermediary role in the integrated framework, a practical example of innovation value chain/network, in the context of MNT, is also included in the study.

The paper proceeds as follows. The next section presents a theoretical framework outlining a systematic literature review and the underlying motivation and driving forces behind the technology-push and market-pull dynamic. We also review the literature on intermediaries and the value chain. Section 3 presents our methodological approach and research design. The empirical findings of intermediary actors and how they facilitate crossing the VOD are outlined in Section 4. The Innovation value chain, in the context of MNT, is also presented in this section. Finally, Section 5 presents discussions and concluding remarks with a note on future research directions.

\section{THEORETICAL BACKGROUND AND LITERATURE REVIEW}

In order to facilitate a consistent approach to reviewing the literature in the area of technology-push and market-pull, we introduced the structured systematic review method. Such reviews were developed by Cochrane in the late 1970s [24]. They differ from standard literature reviews, because they adopt a structured approach to the comparison of studies, instead of simple narratives, which can be biased. A key advantage of systematic reviews is that research work is pooled from a number of sources, and, as such, is more powerful than single data sets. To begin with, the key electronic databases for the subject area were identified using Metalib ${ }^{\mathrm{TM}}$ (Metalib $^{\mathrm{TM}}$ is a meta-search engine that searches across a wide range of electronic databases simultaneously). This search highlighted databases with the largest datasets, which referred to peer-reviewed journal articles. Those selected were - ABI/INFORM (Proquest), Business Source Premier (EBSCO), Scopus and Emerald Library. These electronic references were all accessed via 
Metalib $^{\mathrm{TM}}$. Initial pilot searches were conducted using each database and a number of initial search terms. The relevance of the articles returned was determined by scanning the abstracts. If the search was still identifying too wide a sample, then additional search terms were used, along with limiting strings. To increase the quality of articles returned, the search was restricted to scholarly journals, and peer-reviewed articles only. Furthermore, the range was 1995 to the present, reflecting the novelty of this area and a wish to keep the work up-to-date.

Considering the above systematic review, this section makes a synthesis of literature, in order to build a common understanding of technology-push and market-pull strategies. The concepts were introduced by Schoen in 1967 [19], as the underlying motivation and driving forces behind the innovation of a new technology. Technology-push can be described as creative, and/or destructive, with new or major improvements; while market-pull is a replacement, or substitute [25]. In the first stage of the Marquis model [7], called 'idea recognition', the source of innovation is deemed to come either from the recognition of technological feasibility, that is a 'technology-push', or from the recognition of potential demand, known as 'market-pull'. Another view comes from Abernathy and Utterback [26], stating that radical product and process innovation (technology-push) is subsequently followed by incremental innovations (market-pull). This is in accordance with Pavitt [27], who states that technology is particularly relevant for the early stages of the product life cycle, and market factors, especially for their further diffusion.

It has already been recognized that demand side factors and technology side factors jointly determine a company's R\&D success [28] and, therefore, successful products and services rely on the targeted combination of market-pull and technology-push activities [29], since the integration of push-pull factors generally contributes to more innovation in a company [29]. In fact, it is claimed that the technologypush and the market-pull factors are the primary drivers of technological innovation [21], [30], [31]. The technologypush concept is based on the view that a new scientific discovery will trigger innovations ending with commercialization of a new technology or product. The technology-push concept argues that the users' needs have a relatively minor role in determining the pace and direction of technological innovation. On the other hand, the marketpull concept is based on the view that users' needs are the key drivers of innovation, thereby suggesting that companies should pay more attention to the needs of users [21]. Such a clear-cut differentiation is hard to justify in practice, but remains useful for the sake of this discussion.

In the literature, there are many studies examining the two factors from different perspectives. Rothwell [32] considers technology-push and market-pull as one of the models in the innovation process. He argued that the first generation innovation process was dominated by technology-push, based on the assumption that more $\mathrm{R} \& \mathrm{D}$ will result in more successful new products. This innovation process occurred during the 1950 s to mid -1960 s. But, toward the second half of the 1960s, companies started putting greater emphasis on marketing, as market competition increased. The second generation, or market-pull, model of the innovation process was introduced. According to this model, the market was the main driver for directing R\&D. It was realized that one of the main risks inherent in the market-pull model, was that it could lead companies to neglect long-term R\&D strategies and become locked into a regime of technological incrementalism. As a result, the danger was a loss of capacity to adapt to radical technological changes.

However, empirical studies on successful innovation indicated that the technology-push and market-pull models were extreme and atypical. This led to the generation of the 'interactive', or 'coupling', model of innovation [32]. The model represents the confluence of technological capabilities and market needs. In a similar view, Walsh et al. [25] proposed a disruptive technology innovation model that integrates the technology-push and market-pull theories, and the differentiation between discontinuous or disruptive, and continuous or sustaining, innovations ('continuous' being used as an alternative term for 'incremental'). The model displays four technology/market strategy typologies, two for each technology category and market strategy. Kassicieh et al. [33] differentiate between the commercialization activities of disruptive and sustaining (i.e. continuous) technologies. They found that pursuing the commercialization of sustaining technologies seemed to be focused more on revenue generation and market potential, whereas firms working with disruptive technologies seem to understand the need to develop the supporting infrastructure to create new products. The authors, however, did not explicitly discuss the extent to which those commercialization activities are influenced by market-pull and technology-push factors.

Although there have been extensive studies in the literature discussing such concepts, our systematic literature review highlighted a gap in the literature, suggesting that there is still a need to enhance the concept, particularly when the primary concern is the better understanding of the factors enabling the successful take up and exploitation of emerging and disruptive technologies, such as MNT. An important observation from the literature - highlighting another gap - indicates that most studies consider the technology-push and market-pull theory as the primary drivers of innovation, without making a clear distinction between the types of innovation involved.

Nemet [34] followed a line of inquiry that is similar to ours, in the sense that he questioned the notion of technologypush and demand-pull, when applied to non-incremental technical change. The author, however, emphasizes only demand-pull factors, and considers more specific environments - where demand is largely attributable to actions by governments - as intermediary. In the technology-push approach, the government's goal is to increase the availability of new knowledge, while, in demand-pull, the goal is to increase the size of markets for commercialized knowledge. Examples of technology-push policies include: public $R \& D$ funding, $R \& D$ tax credits, 
subsidizing education, and supporting knowledge networks. Examples of demand-pull include: intellectual property rights, pricing externalities, subsidizing demand, government procurement, and technology standards. Furthermore, where advanced high technologies, such as MNT, are concerned, technological policy interventions are developed at the national level.

This research identified a number of intermediaries, and interviewed them to understand how they contribute and position themselves Vis a Vis the technology-push and market-pull models. Intermediaries possess resources and competencies to conduct technology commercialization and provide technology providers with the opportunity to concentrate on their explorative strengths [35]. Intermediaries play a crucial role, as they help to ensure that technologies can be matched to an industrial firm for exploitation, reduce transaction costs [36] and may therefore contribute to increasing the operational effectiveness of the market for technology [37]. In technology markets, intermediaries are seen as integrated research institutions -providing tools, methods and services that foster knowledge transfer, thus strengthening the innovation process. On the other hand, the key to achieving superior R\&D productivity and speed of innovation and production of top quality products, is through technology integration. As MNT research is a more process-driven approach, technology integration is becoming much more important in the sector. An effective MNT technology integration process may start in the earliest phases of an R\&D project, and provides a road map for later stages of product development. So, gaining and sustaining a competitive advantage in an increasingly complex production system, requires that a company understands the entire value chain, not just the portion of it in which it participates [38]. In summary, a systematic review of recent technology-push and market-pull literature highlighted the following:

- It appears that there are strong interdependencies between technology-push and market-pull models. At the same time, there appears to be a research gap to understand how these approaches are used, to manage the product and process life cycle for MNT, and to develop a tailored framework for such emerging technology.

- Uncertainty is a common factor, referred to when managing the development of new technology paradigms [31], since adoption depends on its successful diffusion.

- A simple overall push-pull approach appears inadequate. Our literature review highlighted a gap for a contemporary integrated technologypush and market-pull model. Such a model would be used to understand the adoption of emerging MNT.

\section{RESEARCH DESIGN AND AN INTEGRATED TECHNOLOGY- PUSH AND MARKET-PULL FRAMEWORK}

The research began with the aforementioned systematic review. This review highlighted a need for a contemporary integrated technology-push and market-pull model. A mixed-methods research approach was adopted for this study, harnessing the diverse range of research approaches, and providing a more holistic view of the area under investigation. The research process is outlined in Figure 1, and the methods of data collection and its analysis steps are provided in Table 1.

In this research, a portfolio of MNT-based R\&D projects, that involve partners in the European Commission FP6 funded 4M Network of Excellence, was used for the survey data collection. To have access to a rich and validated knowledge repository, this portfolio is comprised of 88 R\&D projects spread over 17 different European Union member states focusing on MNT research. The projects involve consortia of industry and $\mathrm{R} \& \mathrm{D}$ partners that are specialists in their fields and have agreed a joint $R \& D$ program. This research has been useful for all parties, in terms of identifying new research activities and specific development projects, either as a reaction to a new capability emerging, as a fine-tuning of existing processes and capabilities to solve a particular problem presented by current process limitations, or as a requirement of operations which may occur later in a given process chain. It also highlights those technologies which will benefit from industry-led testing and implementation to take a product or process to market.

After proposing an integrated technology-push and marketpull framework, we ran a Workshop, comprising a range of eminent academics and senior professionals from research institutes and industry. The 30 participants comprised the 17-strong 4M Executive Board and experts from the 4M partners. The workshop participants were split into three groups. The first group focused on identifying maturity indicators for projects that target the development of

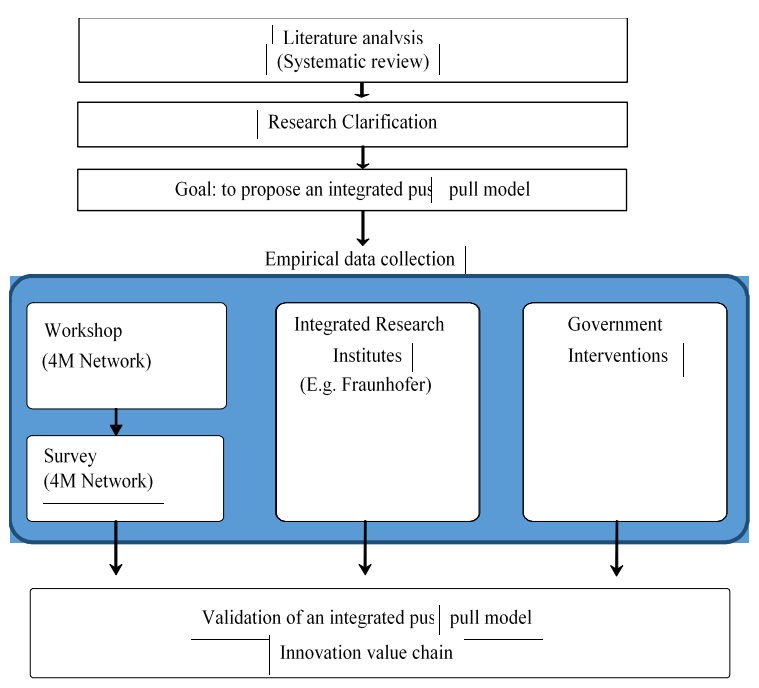

Fig. 1. An outline of the research process 
manufacturing technologies. The second group was asked to focus on projects targeting the development of applications. The third group was dedicated to projects aiming at developing both technologies and applications at the same time. A Delphi study was conducted in the second half of the workshop to identify the key indicators that were then used to develop a self-administered on-line survey questionnaire, as the sample size was relatively large and geographically dispersed.

Many sources of literature [39], [40] were consulted for questionnaire best practice and all of the sources describe how to extract the maximum available information in the optimum time and space. Following several test-runs, which resulted in two rounds of modifications and improvements, the questionnaire was launched online. Participants were asked to specify which MNT was relevant to the project considered. Projects would typically focus on overcoming

TABLE I

DESCRIPTION OF RESEARCH METHODS AND THEIR PURPOSE

\begin{tabular}{|c|c|}
\hline Research Description & Purpose \\
\hline $\begin{array}{l}\text { Literature analysis - } \\
\text { systematic review }\end{array}$ & $\begin{array}{l}\text { - To provide a consistent approach to review a } \\
\text { wide range of literatures covering } \\
\text { technology-push and market-pull, } \\
\text { intermediaries and value chain. }\end{array}$ \\
\hline Research Clarification & $\begin{array}{l}\text { - To create the initial assumptions and divine } \\
\text { how they were shaped by the existing } \\
\text { literature: clarification of the research } \\
\text { gaps (goals) to address. }\end{array}$ \\
\hline $\begin{array}{l}\text { Workshop \& follow-on } \\
\text { 4M survey }\end{array}$ & $\begin{array}{l}\text { - To assist the positioning of EU MNT } \\
\text { projects initiated, or completed, over the } \\
\text { period, with EU, national, institutional or } \\
\text { private funds, on a technology maturity } \\
\text { scale. } \\
\text { - To assess the distribution of research effort } \\
\text { in Europe. }\end{array}$ \\
\hline \begin{tabular}{|l|} 
Face-to-face interview \\
with integrated research \\
institutions (E.g. \\
Fraunhofer) and with \\
government actors
\end{tabular} & $\begin{array}{l}\text { - To explore how an integrated intermediary } \\
\text { research organization transfers research } \\
\text { to markets. } \\
\text { - To understand the role of intermediaries in } \\
\text { government interventions. }\end{array}$ \\
\hline $\begin{array}{l}\text { Semi-structured } \\
\text { interviews with actors } \\
\text { involved in UK } \\
\text { government } \\
\text { interventions. }\end{array}$ & $\begin{array}{l}\text { - To gain a rich understanding of how a } \\
\text { government intervention programme can } \\
\text { be employed to develop MNT facilities. } \\
\text { - To gain a range of perspectives from } \\
\text { industry and research organisations. }\end{array}$ \\
\hline
\end{tabular}

limitations of a given manufacturing technology, to improve and broaden its capabilities, or, more likely, to develop a product incorporating micro and nano features and only utilize one or a set of micro and MNT to produce different components of the developed product. This was particularly important when considering that the project team intended to continue this work in a more industrial context, with those institutes operating in the MNT environment, or with companies utilizing technologies leading toward MNT adoption. Follow-up semi-structured face-to-face interviews were conducted with the actors in the MNT value chain.

A literature analysis was built on the initial conceptions, leading to the research gaps, and requirement for an integrated technology-push and market-pull framework. The use of varied and complementary research approaches enabled us to triangulate data and develop the framework for emerging technologies, such as MNT, as shown in Figure 2. There is a tendency to treat the concepts of technology-push and market-pull as two extreme elements, with new technologies on one side and market demands on the other. Such a model is useful to discuss part of the life cycle of most technologies; however, having researched the area of MNT, from a range of academic perspectives (e.g., engineering and business), we believe this is too simplistic. The proposed integrated technology-push and market-pull framework is being developed to represent the links between emerging micro- and MNT and market demand.

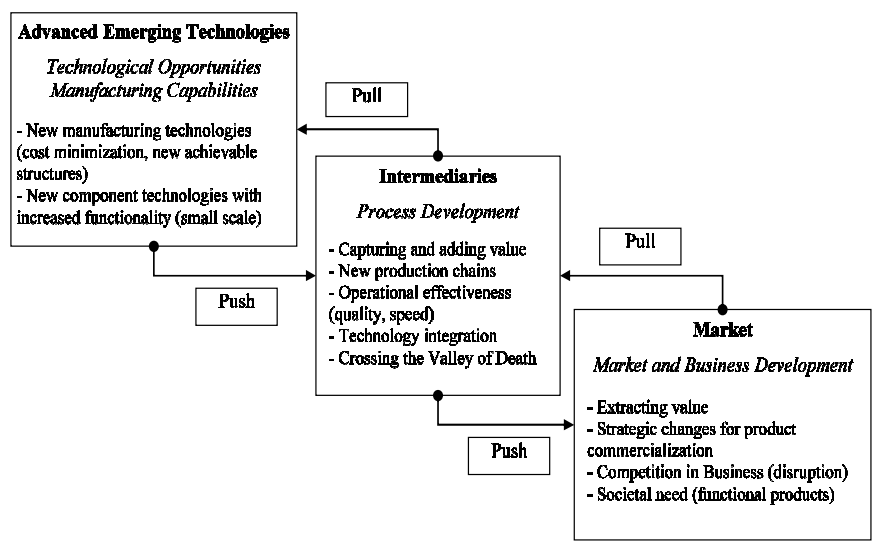

Fig. 2. An integrated technology-push and market-pull framework for emerging technology, such as MNT outline of the research process

When considering emerging technologies such as MNT, it would appear that a clear difference needs to be made between what are described as 'component technologies', and 'manufacturing technologies'. 'Component technology' can be an end-product which can be integrated into new innovative end-products; whereas 'manufacturing technology' enables the development of new component technologies. This model introduces the idea that manufacturing technologies often do not have a direct link with market demand, particularly in the case of research institutions or university departments. It proposes that between them lies an intermediary body, acting as coordinator for the complex design issues inherent, when developing such emerging technologies.

It is implied that the role of this intermediary is to match market opportunities/needs with manufacturing capabilities. While traditionally, this role is taken either by technology providers, e.g. academic institutions or technology companies that supply technological expertise and prototypes, or end-product producer that address environments where speed of innovation determines the success of a company. Nowadays, universities actively seek to foster interactions and spillovers, so as to link research with application and commercialization. As a result, the processes of creation, acquisition, diffusion and deployment of knowledge are at the core of the university's functions 
[41]. This intermediary can in fact take a number of other forms, for example, Business Incubators (they provide an infrastructure to enable early stage ventures to establish their business), Science Parks (value-adding by creating synergetic effects through technology-specific cluster building, via shared knowledge, thereby fostering the direction of technology development), Technology Transfer Offices (value-adding based on direct commercialization of IP objects), technology brokers and consulting companies.

Many firms experience great difficulty in capturing value from open innovation, using intermediary services. In contrast, a few firms, such as Procter \& Gamble, achieve substantial benefits from collaborating with several intermediaries [42]. This study suggests that these differences are strongly affected by the firms' level of collaboration with intermediaries and the technology under development. This is emphasized in the integrated framework in Figure 2. In a number of cases, EU funding bodies and numerous governments have deemed the problem to be of such importance that they have intervened with funding programs and/or interventions.

\section{FINDINGS}

\section{A. Network of research organizations}

The importance of intermediaries has grown in recent years because manufacturing firms have increasingly attempted to acquire and transfer technology. Despite the growing importance of innovation intermediaries, prior academic research into this field is relatively limited [43]-[45]. In addition, prior work on the technology transfer activities of manufacturing firms has hardly examined the role of intermediaries [46]. On this basis, the paper attempts to deepen our understanding of the role of intermediaries in crossing the VOD and to examine the value chain of manufacturing firms and intermediaries in the context of MNT. We also show how actors actively collaborate with intermediaries in capturing and extracting value, by opening up their innovation processes.

A good example of the network of research organizations is the $4 \mathrm{M}$ Network, which seeks to integrate fragmented European R\&D capacity, in non-silicon micro technologies, into a European Centre of Excellence. It is designed to help European companies engage with the growing demand for micro- and nano-technology, by supporting their development of batch-manufacture of micro-components and devices in a range of materials. The $4 \mathrm{M}$ network acts as an intermediary, as defined in Figure 2. It should be noted that the vast majority of the partners were research institutions. Due to the complexity of the manufacturing processes considered, and the fact that these institutions are recognized as leaders in their respective fields in Europe, we believe that their involvement in the technology-push and market-pull balance should be representative. Of 88 European projects, 81 research projects gave sufficient budget information on both total budget, building up to a total budget of 242 million Euros, and industrial contribution, to allow us to draw an interesting picture of the types of 'intermediary' stimulating MNT's R\&D in Europe. Five types of such 'intermediary' were identified, namely the Industry, the R\&D Institutions (Institutional), Regional Funding bodies, National Funding bodies, and European Funding bodies (EU).

Figure 3 shows the distribution of projects per intermediary, the biggest contributor appears to be National Funders, followed by the EU Funders. However, looking at the budget distribution per intermediary (Figure 4), the EU appears to be the most significant funder followed by National Funders, leaving other types almost negligible. The total industry-led budget is less than 1\% (Figure 4), and the industry contribution appears significant only within public-led budgets (Figure 6).

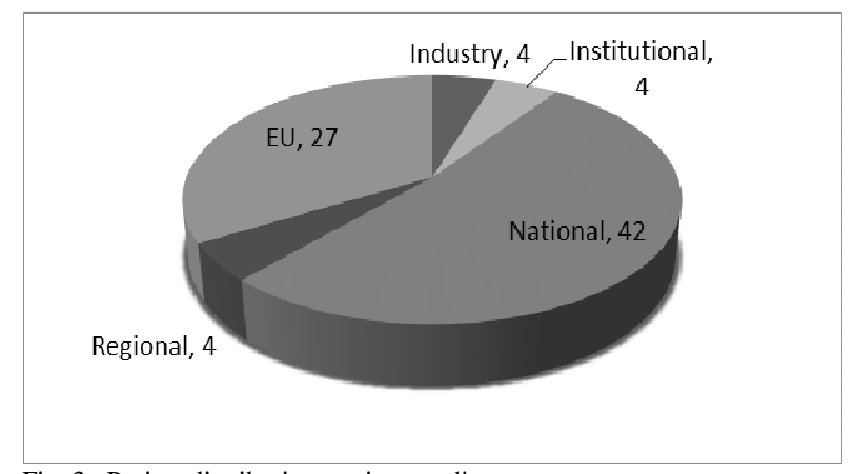

Fig. 3. Project distribution per intermediary

More specifically, as illustrated in Figure 5 and 6 , it is important to distinguish between the projects that focused on the development of new products only (without research in manufacturing processes), the projects that focused on the development of new manufacturing processes (without focusing specific product) and those that focused on both. With this in mind, at almost 34 million Euros the Industry contribution to this portfolio of research projects reaches 14\%. As shown in Figure 6, 59\% of contribution were for research projects focusing on both the development of new products and new manufacturing processes; $30 \%$ were for projects focusing on the development of novel manufacturing processes; and only $11 \%$ were for projects focusing on the development of new functional products. This could be interpreted as an interesting direct marketpull dynamic, where new manufacturing technologies are developed concurrently with the design of new products $(59 \%)$.

The industry contribution mentioned above was mostly part of a wider funding scheme organized by another so-called intermediary, generally the EU, where $50-60 \%$ of industry contributions (Figure 6) and the total budgets (Figure 5) were dedicated to concurrent research for both process and product development. These figures demonstrate that the development of these MNT benefit strongly from intermediaries bringing together manufacturing capabilities and marketable products. There are only a few industry-led projects, to which the surveyed institution took part, and this could be explained by the high risk, linked with the use 
of emerging MNT and because an intermediary helps in minimizing said risk.

The interesting finding is that, generally, research budgets in 'processes research' are higher than in 'product research', which is to be expected, for research institutions. However, looking at the industry contribution, this is still strongly the case for EU-funded projects, with $2 \%$ contribution for products research and $37 \%$ for processes research, but is totally the opposite for Nationally funded projects, with $3 \%$ contribution for 'processes research' and 37\% for 'products research' (see Figure 6). This might reflect different funding priorities, depending on the intermediary.

These different types of intermediary services strongly affect the issue of how manufacturing firms may successfully collaborate with the intermediaries. Based on the multiple types, many manufacturing firms are now willing to pursue technology transfer more actively. The role of intermediaries (e.g. business incubator, technology broker) thus have a significant impact on the success of manufacturing firms. This study provides an example on how the role of intermediaries improves the production and commercialization speed, as well as the quality of the endproduct. The studied company, based in Oxford, UK, is a global provider of laser processing equipment and manufacturing services for the fiber optic and micromachining markets. They have an impressive track record of developing new and novel laser processes, on the micro and nano-scale, and of transitioning these into robust and cost effective production-line solutions in microelectronics, photonics and precision engineering. The intermediaries help accelerate the speed with which product design ideas can be assessed, and/or parts modified, using lasers. The use of laser-based micro and nano-manufacturing allows the high-volume stage to be reached quicker and allows the client to choose the right time to commit to the full production stage.

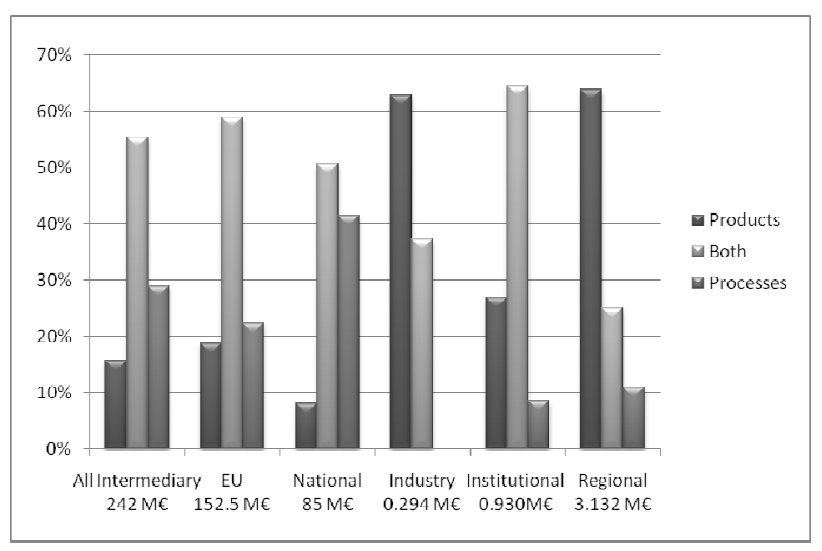

Fig. 5. Project budgets distribution per intermediary

The company can be considered a niche manufacturer, due to its high-end products requiring in-depth technical expertise, along with an expensive unit cost, and it attaches more importance to quality and customer satisfaction, because they see it as giving them a competitive edge. Trust

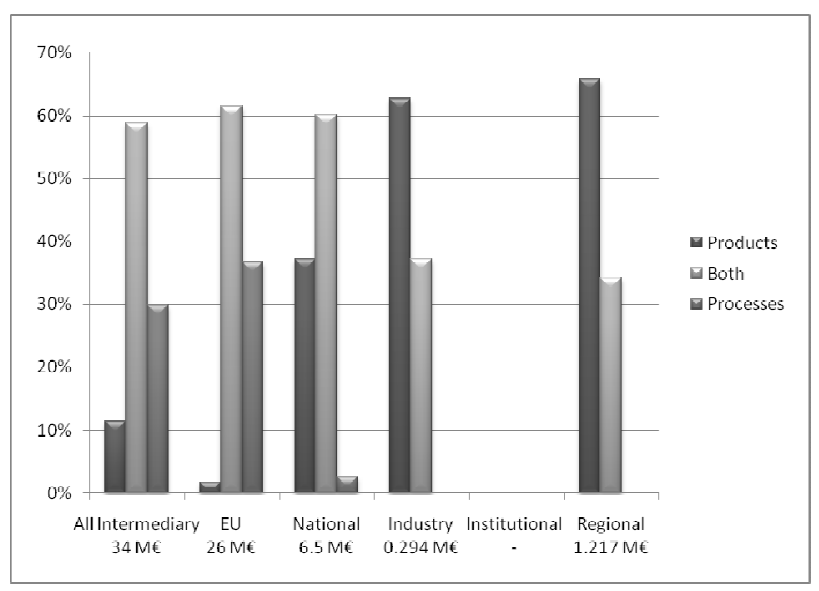

Fig. 6. Industry contribution per intermediary

and close relationship building with customers are one of the driving forces of the company's performance. The senior management work closely with intermediaries and customers as part of the day-to-day running of the business. It is worth noting that laser micro and nano machining and/or processing are becoming important in product development plans across industries.

\section{B. Government interventions}

The purpose of analyzing government interventions, based on interview data analyses, is to highlight the role of intermediaries in the MNT sector. In the US, MNT is recognized as a critical technology for the 21 st century and considered to be at the early stage of exploitation. Both federal and local government funding, via intermediary bodies, support interdisciplinary research teams, including long term fundamental science and engineering research for translation into useful applications. The intermediaries have channeled the research funds into the creation of academic centers of excellence, rather than university-industry collaborations. R\&D infrastructure, including a nationwide network of shared-use facilities called the National Nanotechnology Infrastructure Network (NNIN) was also established for transforming MNT research into useful applications. Outside the NNIN, various public and private funding agencies, as intermediaries, are also involved. These intermediary organizations, which sit between businesses and the university sector, perform many functions, including foresight and diagnostic analysis, various kinds of accreditation, validation and regulation, and finally, activities connected more directly with the commercialization process in the MNT sector.

In Japan, the focus is on involvement of both the public and the private sector, as opposed to the US where industry makes most of the decisions in the later stages of the innovation process. Government organizations and very large corporations are the main source of funding for MNT, while small and medium-sized companies play a minor role. The role of intermediaries in the Japanese MNT system was 
strengthened through the recent Science and Technology Basic Plan initiated by government, bridging public and private research and knowledge transfer. Internal intermediaries, for example, technology licensing offices (TLO) have proliferated in Japan, after the Bayh-Dole Act (1980) granted US universities the right to appropriate and commercially exploit knowledge generated by, or jointly with, academic departments. After conducting a series of 25 face-to-face interviews with the actors both in public and private sectors, some suggestions have been made. For example, government need to make continuous investment in research, in a competitive manner, among research groups in MNT, to maintain their country's competitiveness. To overcome the barriers between early technology breakthroughs and products in the MNT sector, continuous government funding and its proper utilization could make the difference between shelf technology and a commercial success.

On the other hand, the UK government drew up plans to address the technology gap in the UK market for MNT, and an intervention and innovation program followed [35], creating a regionally-dispersed network of MNT facilities. This network was created to provide UK businesses with access to the latest range of MNT services and capabilities within key sectors; an example of a mechanism by which a public body has attempted to fill the void between technologies and application, and therefore this fits in the 'intermediary' box of Figure 2. We have collected data from 28 key stakeholders from the intervention network. Stakeholders ranged from the 'architect' of the centers, through to regional development technology managers, MNT center CEOs/Directors, and the government auditors of the program. Overall, interviewees consider that government intervention has been favorable, with a few exceptions. Examples were given where products could not have developed without access to these MNT centers; one particular example saw the development of a micro-fluidic device used in a piece of analysis equipment for the pharmaceutical sector. However, conditions placed on the MNT centers from the administered grants, meant that the ability of some centers to bridge the commercialization gap from technology-push to technology application was difficult. A number of interviewees, with vast experience of developing new technologies, talked of time periods ranging from at least seven years and upwards from idea to endproduct. Partly, this depends upon the level of initial risk, or 'newness' the technology exhibits, i.e. more developed technologies are likely to be applied far quicker, whereas truly 'emerging' technologies are likely to need a long period of funding and development. The need for intermediaries to consider realistic developmental timescales must also be considered, to meet the balance between technology-push and market-pull. The complexity of the intermediary in meeting the customers need emerged as an important theme. A number of centers described the situation where customers often do not understand what they need; or the difficulties of communicating what can be achieved with an emerging technology such as MNT, and what is required. This is a reflection of the complexity of developing emerging MNT.

\section{Crossing the Valley of Death}

In the survey, MNT research projects were classified under six non-exclusive design and manufacturing R\&D categories, namely: 1) New product, 2) New manufacturing technology, 3) New manufacturing process chain, 4) Improved product, 5) Improved manufacturing technology, and 6) Development of improved manufacturing process chain. Figure 7 shows the number of surveyed projects falling under each of these six categories. It is interesting to note from the survey data analysis that the majority of these projects are focused on new developments, rather than on improvements, which stresses the innovative 'content' of the field. The findings show that $62.5 \%$ of these projects were focusing on new or improved products based on micro-manufacturing technologies. The remaining $37.5 \%$ were focusing only on developing the capabilities of the manufacturing technologies themselves. This survey result shows the expected product innovation potential, but $41 \%$ of the projects were both focusing on product and technology development, while for only $21.6 \%$ of the projects were the manufacturing technologies considered mature enough to produce the products. Thus, these product concepts appear to mainly sit at the early stages in the innovation process, where the VOD generally appears. While more than $60 \%$ of the projects involved industrial partners contributing to around $14 \%$ of the total funding as stated in section 4.1, the actual total amount in the privatelyled budgets was relatively low when compared with the publicly-led budgets. For an unbiased analysis, more information on privately funded projects would be required; however these figures suggest that many product innovations based on MNT are still relying on public funding to escape from the VOD. The reason for this is, most probably, the high risk involved when integrating into product functions requiring multidisciplinary micro manufacturing expertise, and the development or improvement of micro manufacturing technologies.

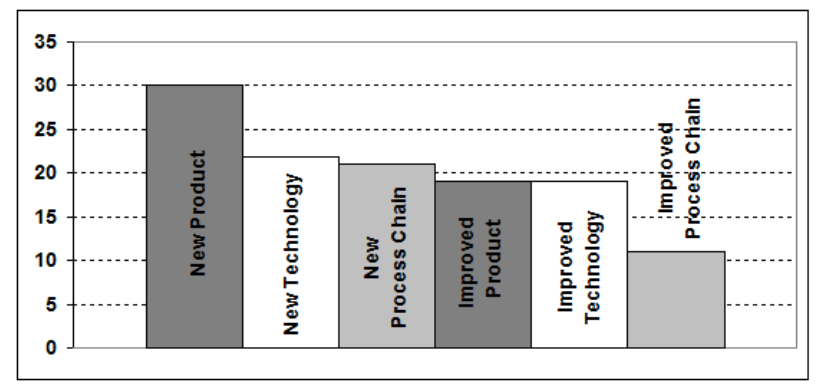

Fig. 7. Number of projects per theme

Thus, it seems that MNT are still not fully integrated in the market-pull and technology-push dynamic. The existence of the VOD in MNT development is confirmed in our survey, suggesting that the intermediary role is crucial 
to escape from this VOD, turning the technologies to their full innovative potential. This supports our proposition of including the intermediary role in the technology-push and market-pull dynamic.

\section{Innovation value chain in the context of MNT}

As stated in Figure 2, the integrated technology-push and market-pull model suggests that innovations in MNT are complex and necessitate different players performing different functions, at the market demand end, the advancement of technologies at the other end, and the intermediary functions between those two ends. A more formal framework, that is relevant in analyzing such complex and multi-disciplinary innovation processes in MNT, is the so called 'innovation value network'. Adner and Kapoor [48] define a value network as the collaborative arrangements through which firms or organizations combine their individual offerings into a coherent, customer-facing solution. The value network concept offers a comprehensive view of understanding how the innovation processes in MNT can, and should, be broken down into different interrelated and inter-dependent processes, and what values the different players could offer without which successful MNT adoptions could never be realized.

In the case of MNT, as confirmed by the results of our interviews and survey, new manufacturing technologies, or new market opportunities, that have emerged quite often, only send weak and ambiguous signals to the other end. This is particularly true when the expected successful innovation needs to overcome many complex design issues. Using the value network concept, we argue that the intermediary roles carried out by actors, who belong to the middle box, are crucial in turning opportunities, emerging either from a new technology or market demand, into a successful innovation.

An example of a value network in the context of MNT is used to support our argument on the importance of the intermediary role in the technology-push and market-pull model. The example is based on SEMOFS, a project funded by the European Commission through the Sixth Framework Programme for research and technological development involving five research partners, two industrial partners and an end-user (hospital). Motivated by the general trend towards more decentralized and immediate diagnostics for health, the project's main aim is to develop a next generation of polymer-based label-free biosensors through the combination of innovative plasmonics, integrated optics (light source, detection) and micro-fluidics. This will be a significant breakthrough, since all functions will be totally integrated on a single polymer-based chip. When reaching mass production capability, the chip will be extremely low cost and disposable, while providing increased sensitivity and diagnosis possibilities.

The project can be seen as an innovation value chain of many inter-connected pieces and players. Figure 8 shows the value chain representation of the project. The main contributing role and the associated partners as follows:
- Plasmonics: to enhance the surface-plasmon resonance (SPR) sensor, enabling label-free optical detection system

- Active Micro Optics: to fully integrate active and passive optical components

- Functionalisation: to accommodate biotechnological functionalisation of a sensor surface through the creation of a chemical interface between the sensor surface and the antibody

- Active Micro Fluidics: to produce biocompatible microfluidics with integrated fluidic actuators

- Integration: to integrate all the functions onto a polymer chip

- Industrial applications

- Proof of concept

- Main funder and facilitator: European Commission

While Figure 8 depicts the project as an innovation value network, the actual interdependent relationships between different partners are much more complex, which suggests that many issues exist in trying to optimally match the market demand requirements (medical application) with the technological capabilities available within the research centers. This example shows that such a promising innovation is only made possible by the intervention and facilitation carried out by the European Commission, which highlights the importance of the intermediary in the innovation processes, as we proposed in the framework.

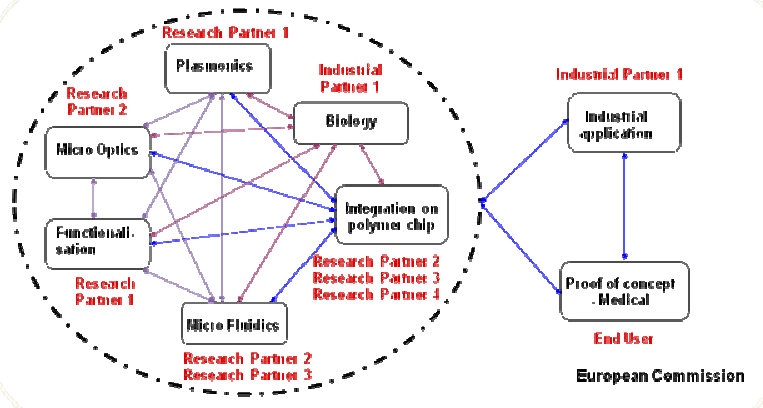

Fig. 8. Example of an MNT innovation value network

This supports our proposition that the innovation model, taking into account the dichotomy of push and pull-factors, is too simplistic and incomplete. The concept of an innovation value network is also relevant to revitalize the important roles that small firms can play in realizing successful MNT adoption.

\section{DISCUSSIONS AND CONCLUSION}

There is a great deal of research on MNT innovation. However, there has not been any comprehensive theory developed on how to conceptualize technology-push and market-pull on an abstract level, combining the various research results. This paper attempts to address this gap, and can be used as a benchmark for micro and nanotechnology practitioners and policy makers. In this paper, 
some important issues related to the understanding of the current implementation behavior of MNT were discussed. The need for a pragmatic, integrated technology-push and market-pull model was highlighted, in order to better represent the links between emerging MNT and market demand. While the market potential is clear, due to the emerging nature of innovations, they tend to be highly driven by $R \& D$ organizations, rather than by industry. The model proposes that an intermediary body lies between these two extremes, to act as coordinator: matching opportunities and needs with manufacturing capabilities. Traditionally, this role is taken either by a technology provider or an end-product producer. However, other important intermediaries exist - such as publicly-funded programs, business incubators, technology transfer offices, technology brokers - as discussed in this paper.

An interesting finding is that research budgets in 'process research' are higher than in 'product research', which is to be expected for research institutions. If we looked for industrial contribution, this is true for the EU-funded project, but the opposite for nationally-funded projects. This might reflect different funding priorities of intermediaries. It is worth consulting the study by Linton and Walsh [49] who suggest that process-based innovations, such as MNT, require a new innovation model from the models developed based on assembled products. For process-based products, product and process innovation are tightly coupled, i.e. a change in the manufacturing process is expected to result in a significant change in the product, which highlights the increasing importance of coordination between 'processresearch' and 'product research'. The survey results in this paper, with two totally different profiles between EUfunded and nationally funded projects, may raise a question as to what extent coordination between funding bodies has taken place, to ensure that the benefit of the research investment is maximized.

The paper has shown that new manufacturing technologies, for example, new component technologies with increased functionality, do not have a direct link with market demand and need an intermediary body for new product development and commercialization. It is implied that the role of this intermediary is to match market opportunities/needs with manufacturing capabilities. In recent years, such an intermediary - the Fraunhofer Institute in Germany - has supported both technology-push and market-pull, by undertaking contract research for MNT for the public sector, government, and industry, including small and medium-sized enterprises (SMEs), which lack the critical mass to carry out their own R\&D. They have acted as an adviser to government and industry on researchrelated issues, particularly on the commercialization of emerging or new technologies and have directed pinpoint areas of activity meant to facilitate innovation and the quick translation of ideas into high-quality products. In order to maximize their potential as an intermediary body, they have formed cooperative alliances that jointly offer their services as well as advising executive boards on structural and business development within their emerging research fields.
As a result, they were able to continuously transfer technologies and expertise into industry. To promote the transfer of research into industrial applications, they established: Application Centers, Innovation Centers and Demonstration Centers. However, the complexity of meeting customers' needs emerged, as highlighted in the UK case.

We have also demonstrated that our view on the complexity of the MNT innovation processes, and the importance of the intermediary role, is well supported by the formal concept of a value network. The complete overview of SEMOFS case, of the value chain of research and technology transfer processes, highlights the importance of an integrated framework and intermediaries in which multidisciplinary groups and organizations work together. The value chain really highlights the importance of systematic thinking; the MNT successful innovations would require collaboration between different players at the market demand end, the advancement of technologies at the other end, and the intermediary functions between those two ends. Through the example case of a European Commission funded project, we have demonstrated the existence and the significance of such a network. This paper has sought to contribute to the analysis on how intermediaries facilitate the interaction between various actors involved in the process of technology diffusion, to crossing the VOD in the context of MNT, an issue that has gone largely unaddressed in the literature. What is required is closer and more regular collaboration between actors, in order to achieve commercial success in emerging technology, and a significant freedom to interact with intermediaries is highly recommended, in line with Juanola-Feliu et al. [8]. Although this analysis is undertaken in the MNT sector, it is believed that the presence of technology integration, and the relationship between the role of intermediaries and the VOD, are relevant to other, science-driven high-technology industries, such as the emerging field of nanotechnology.

As our suggestion for further research, it would be worth mapping different players that belong to each of the three elements of the integrated push-pull model and identifying the extant interrelationships between them. The result of this process will help technology policy makers prioritize the type of research projects and/or research organizations that should be funded. Furthermore, this mapping process will also help identify whether sustainable value networks have been created. In relation to this, for example, the responses obtained from our survey suggest that $72 \%$ of project consortia agree that their work is a part of the value network, particularly in the development of new products. However, there is insufficient information from that study to assess the success rates of those projects and to conclude which aspects in the network have contributed to the successes and which obstacles have contributed to the failures. As suggested by Adner and Kapoor [48], it is important to identify whether primary obstacles lie upstream or downstream of the intermediary element. Upstream obstacles act as barriers to production, and in contrast, downstream obstacles act as barriers to adoption. The 
policy makers can continuously play their strategic roles, serving as catalysts for overcoming such obstacles. Further work would include additional survey data, from privatelyfunded projects, to further validate the integrated framework presented in this paper.

\section{REFERENCES}

[1] European Commission, 2010. Europe 2020 flagship initiative innovation union. COM (2010), 546 final.

[2] F. Kodama, "Direct and indirect channels for transforming scientific knowledge into technical innovations," in Transforming scientific ideas into innovations: Science policies in the United States and Japan, Eds. B. Bartocha and S. Okamura (Tokyo: Japan Society for the Promotion of Science), 1985, pp. 198-204.

[3] S. T. Walsh, "Roadmapping a disruptive technology: A case study of the emerging microsystems and top-down nanosystems industry". Technological Forecasting and Social Change, vol. 71, pp. 161$185,2004$.

[4] S. T. Walsh and J. D. Linton, "Infrastructure for emerging markets based on discontinuous innovations," Engineering Management Journal, vol. 12, no. 2, pp. 23-31, 2000.

[5] J. L. Bowler and C. M. Christensen, "Disruptive technologies: Catching the wave", Harvard Business Review, vol. 73, no. 1, pp. 43-53, 1995

[6] C. M. Christensen, The Innovator's Dilemma: When New Technologies Cause Great Firms to Fail. Boston, USA: Harvard Business School Press, 1997.

[7] D. G. Marquis, "The anatomy of successful innovations," in Readings in the management of innovation, M. L. Tushman and W. R. Morre, Eds., Ballinger, Cambridge, MA. USA, 1969, pp. 7987.

[8] E. Juanola-Feliu, J. Colomer-Farrarons, P. Miribel-Catala, and J. Valls-Pasola, "Market challenges facing academic research in commercializing nano-enabled implantable devices for in-vivo biomedical analysis," Technovation, vol. 32, pp. 193-204, 2012.

[9] M. Kautt, S. T. Walsh and K. Bittner, "Global distribution of micronano technology and fabrication centres: A portfolio analysis", Technological Forecasting and Social Changes, vol. 74, no. 9, pp. 1697-1717, 2007.

[10] A. D. Romig Jr., A. B. Baker, J. Johannes, T. Zipperian, K. Eijkel, B. Kirchhoff, H. S. Mani, C. N. R. Rao, S. Walsh, "An introduction to nanotechnology policy: Opportunities and constraints for emerging and established economies", Technological Forecasting and Social Changes vol. 74, no. 9, pp. 1634-1642, 2007.

[11] IPMMAN Roadmap for micro and nanomanufacturing, Eds. A. Almansa, C. Wogerer, H. Rempp and M. Gebauer, version 2.0, 2006

[12] N. Islam and K. Miyazaki, "An empirical analysis of nanotechnology research domains", Technovation, vol. 30, pp. 229-237.

[13] D. de Beer, G. Booysen, L. Barnard, and M. Trustcott, "Rapid tooling in support of accelerated new product development", Assembly Automation, vol. 25, no. 4, pp. 306-308, 2005.

[14] P. Auerswald and L. Branscomb, "Valleys of Death and Darwinian Seas: Financing the invention to innovation transition in the United States", Journal of Technology Transfer, vol. 28, no. 3-4, pp. $227-$ 239, 2003.

[15] S. Markham, "Moving Technologies from Lab to Market", Research Technology Management, vol. 45, no. 6, pp. 31-42, 2002.

[16] C. Frank, C. Sink, L. Mynatt, R. Rogers and A. Rappazzo, "Surviving the Valley of Death: A Comparative Analysis", Journal of Technology Transfer, vol. 21, no. 1-2, pp. 61-69, 1996.

[17] S. E. Cohen, "Adopting innovations in a technology push industry," Res. Manag., vol. 24, pp. 26-31, 1981.

[18] J. M. Utterback and W. J. Abernathy, "A dynamic model of process and product innovation," $O M E G A$, vol. 3, no. 6, pp. 639-656, 1975.

[19] D. A. Schoen, Technology and Change: the New Heraclitus. NY, USA: Delacorte Press, 1967.

[20] E. Von Hippel, "Appropriability of innovation benefit as a predictor of the source of innovation," Res. Pol., vol. 11, no. 2, pp. 95-1 15, 1982.
[21] R. W. Zmud, "An examination of "Push-Pull" theory applied to process innovation in knowledge work," Manag. Sci., vol. 30, no. 6, pp. $727-738,1984$

[22] H. Munro and H. Noori, "Measuring commitment to new manufacturing technology: Integrating technology push and marketing pull concepts", IEEE Transactions on Engineering Management, vol. 35, no. 2, pp. 63-70, 1988.

[23] R. Adner, "Match your innovation strategy to your innovation ecosystem”, Harvard Business Review, pp. 98-107, April, 2006.

[24] A. L. Cochrane, "A Critical Review with Particular Reference to the Medical Profession," in Medicines for the year 2000. London: Office of Health Economics, pp. 1-11, 1979.

[25] S. T. Walsh, B. A. Kirchhoff, and S. Newbert, "Differentiating market strategies for disruptive technologies", IEEE Transactions on Engineering Management, vol. 49, no. 4, pp. 341-351, 2002.

[26] W. J. Abernathy and J. M. Utterback, "Patterns of industrial innovation", Technology Review, pp. 41-47, 1978.

[27] K. Pavitt, "Sectoral patterns of technological change: towards a taxonomy and a theory", Research Policy, vo. 13, pp. 343-373, 1984.

[28] C. Y. Lee, "A simple theory and evidence on the determinants for firm R\&D", Economics of Innovation and New Technology, vol. 12, no. 5, pp. 385-396, 2003.

[29] A. Brem, K-I. Voigt, "Integration of market pull and technology push in the corporate front end and innovation managementInsights from the German software industry", Technovation, vol. 29, no. 5, pp. 351-367, 2009.

[30] D. Mowery and N. Rosenberg, "The influence of market demand upon innovation: a critical review of some recent empirical studies". Research Policy, vol. 8, pp. 102-153, 1979.

[31] G. Dosi, "Technological paradigms and technological trajectories". Research Policy, vol. 11, pp. 147-162, 1982.

[32] R. Rothwell, "Towards the fifth-generation innovation process". International Marketing Review, vol. 11, no. 1, pp. 7-31, 1994.

[33] S. K. Kassicieh, S. T. Walsh, J. C. Cumings, P. J. McHorther, A. D. Romig and W. D. Williams, "Factors differentiating the commercialization of disruptive and sustaining technologies", IEEE Transactions on Engineering Management, vol. 49, no. 4, pp. 375387, 2002.

[34] G. F. Nemet, "Demand-pull, technology-push, and government-led incentives for non-incremental technical change", Research Policy, vol. 38 , no. 5, 700-709, 2009.

[35] D. Gredel, M. Kramer, B. Bend, "Patent-based investment funds as innovation intermediaries for SMEs: In-depth analysis of reciprocal interactions, motives and fallacies", Technovation, vol. 32, pp. 536549, 2012.

[36] A. Gambardella, P. Giuri, and A. Luzzi, "The market for patents in Europe", Research Policy, vol. 36, pp. 1163-1183, 2007.

[37] Gans, H.R., Stern, S., 2003. The product market and the market for "ideas": commercialization strategies for technology entrepreneurs. Research Policy 32, 333-350.

[38] A. Amir-Aslani, S. Negassi, "Is technology integration the solution to biotechnology's low research and development productivity?" Technovation, vol. 26, pp. 573-582, 2006.

[39] A. Bryman, E. Bell, Business Research Methods, Oxford, UK: Oxford University Press, 2008

[40] M. Saunders, P. Lewis, and A. Thornhill, Research Methods for Business Students, Harlow, UK: Prentice Hall, 2006.

[41] E. Juanola-Feliu, "The nanotechnology revolution in Barcelona: innovation and creativity by universities", International Management, vol. 13, pp. 111-123, 2009.

[42] L. Huston and N. Sakkab. "Connect and develop: Inside Procter \& Gamble's new model for innovation", Harvard Business Review, vol. 84, no.3, pp. 58-66, 2006.

[43] D. F. Spulber, Market microstructure: Intermediaries and the theory of the firm. Cambridge, UK: Cambridge University Press, 1999.

[44] Y. Tran, J. Hsuan and V. Mahnke, "How do innovation intermediaries add value? Insight from new product development in fashion markets", $R \& D$ Management, vol. 41, no. 1, pp. 80-91, 2011. 
[45] Y. Zhang and H. Li, "Innovation search of new ventures in a technology cluster: The role of ties with service intermediaries", Strategic Management Journal, vol. 31, no.1, pp. 88-109, 2010.

[46] J. L. Cummings and B. S. Teng, "Transferring R\&D knowledge: The key factors affecting knowledge transfer success", Journal of Engineering \& Technology Management, vol. 20, pp. 39-68, 2003.

[47] House of Commons (Science and Technology Committee), "Too little too late? Government Investment in Nanotechnology", Fifth Report of Session 2003-04, vol. I, HC56-I, 2004.

[48] R. Adner and R. Kapoor, "Innovation ecosystems and the success of early movers in technology transitions: Evidence from the semiconductor lithography equipment industry", 1962-2004, INSEAD Working Paper, 2006.

[49] J. D. Linton and S. T. Walsh, "A theory of innovation for processbased innovations such as nanotechnology," Technological Forecasting and Social Change, vol. 75, no. 5, pp. 583-594, 2008. 